\title{
Humanitarian Action and Intra-Continental Migrant Children's Education: Evidence from the Governance at the Grassroots in Nigeria
}

\author{
Taiwo Akanbi Olaiya ${ }^{1}$ \\ ${ }^{1}$ Department of Public Administration, Obafemi Awolowo University, Ile-Ife, Nigeria \\ Correspondence: Taiwo Akanbi Olaiya, Senior Lecturer \& Researcher, Department of Public Administration, \& \\ Vice Dean of the Faculty of Administration, Obafemi Awolowo University, Ile-Ife, Nigeria. Tel: 234-80-3344- \\ 7396. E-mail: olaiyata@oauife.edu.ng
}

Received: June 14, 2020 Accepted: July 7, 2020 Online Published: August 8, 2020

doi:10.5539/par.v9n2p1 URL: http://dx.doi.org/10.5539/par.v9n2p1

\begin{abstract}
How does humanitarian action at the grassroots shape support for children of intra-continental migrant? Despite a large volume of research outputs and public policy advocacy on migration, there has been little work on the crucial nexus between local humanitarian efforts and migrant children's educational needs. Conceptually, we viewed humanitarian action beyond the traditional definition as a tool for emergency response. We included efforts aimed at dignifying migrant children with basic education and enhancement of their integration in the new location. Cross-sectional data obtained from agencies of government at the grassroots were employed to measure the effects of local humanitarian action on the education of migrant children. The finding showed that institutionalised humanitarian efforts provide real-time support for basic education of migrant children. Also, burdensome obligations and lack of financial independence for governance at the grassroots curtailed the magnitude of assistance rendered by local authorities. Using Talcott Parson's functionalist theory, we suggested three mutually transformative approaches. First, constraints by the upper levels of government- State and Federal tiersexacerbate financial incapacitation and, ultimately, impede humanitarian effort at the grassroots. Second, provision of critical humanitarian needs, such as migrant children's education, fosters social integration and crime control among migrants. Finally, intra-continental migration is not debased by acculturation. The findings showcase the need for strengthening the financial capacity of governance at the grassroots to reinforce common interests between migrants and host communities.
\end{abstract}

Keywords: migrant children, intra-continental migration, governance at the grassroots, humanitarian action, Nigeria; globalisation

\section{Introduction}

Few would question the truism that the human migration, in gregarious droves or solitary undertakings, is historic and phenomenal. Movement of the people across the global divides is, perhaps, inevitable in the lights of modern possibilities and uncertainties. Save for outbreaks of pandemics such as Ebola in parts of Africa, the SARS, and the current global COVID-19 that have conditioned states to close inbound and outbound borders, human migration would most likely continue unhindered. The opportunity provided by faster transportation systems on land and sea, and by air travels undoubtedly raised human penchants to venture out of economically strained areas or for exploring the pleasantries of tourism and visitations across the globe. By the same token, the timeous decisions to flee disease-infested zones or politically vulnerable regions of the globe to desirable areas have become a matter of the mind. The truism becomes more ascertainable, due to the economic onslaught that globalisation and its 'global village offshoot' imposed on modern human.

The 'global village', was coined and popularised by Marshall McLuhan in his books "The Gutenberg galaxy: The making of typographic man" (1962) and "Understanding media: The extensions of man" (1964). In the latter, the author casts "a metaphor" of global interdependence "for our planet reduced in all aspect" (1964, p. 562) and yet simultaneously expanded as never before. In the words of Dixon (2009), the world is "shrinking and expanding at the same time due to pervasive technological advances that allow for instantaneous" and "dazzling marketplace where countries of all economic opportunities are represented and where more fortunate countries come to the aid of less fortunate ones with humanitarian efforts". Authors (Flew \& Losifidis, 2020; Cox, 2018; Rodrik, 2018; Bergh \& Gustafsson, 2019; Terry, 2019) have however submitted that the greatest threat to globalisation, nay 
migration, is coming from the West that originally muted and benefitted immensely from the economic idea. The entire global village, most notably the co-opted citizens of the global south, appears dumbfounded that the beneficiaries (Northern Hemisphere) who produced the goods and services worth globalising could turn full circle to pursue nationalistic agenda and populism. Countries in the West, not all but certainly the influential ones, are wittingly or unwittingly shooting at the very labyrinth of 'global village' through the populism wave in various parts of Europe and, most importantly, by American President Donald Trump's 'America first'.

The planet earth endows different parts of the globe with its allures and strains. Adam Smith identified the indispensability of a part in the whole in the celebrated book, The Wealth of Nations, published in 1776. The classical economist deduced that it portends economic danger when a country either "neglects or despises foreign commerce" or go into restricting "vessels of foreign nations into one or two of its ports only" (Smith, 1776, p. 112). Besides, socioeconomic and political manifestations vary from regions to regions. Reputable authors have, therefore, pointed out that the absence "equality in the global village" (Pieterse, 2003, p. 172) and hostile political regimes occasioned by "media and imperialism in the global village" (Osman, 2019, p. 280) are the main factors prompting modern migration from debauched areas to suitable regions. As Scott (2001) argued, despite the promises occasioned by "mainstream economic thoughts" that globalisation will bridge economic prosperity and income gap across world divide "as the 'global village' grows and market integration and prosperity take hold, the evidence paints a different picture" (p. 160). The realities as they currently hold is that
"Average incomes have indeed been growing, but so has the income gap between rich and poor countries. Both trends have been evident for more than 200 years, but improved global communications have led to increased awareness among the poor of income inequalities and heightened the pressure to emigrate to richer countries. In response, the industrialised nations have erected higher barriers against immigration, making the world economy seem more like a gated community than a global village" (Scott, 2001, p. 160. Emphasis mine).

Since humans could, by mere whims, "live, not just amphibiously in divided and distinguished worlds, but pluralistically in many worlds and cultures simultaneously" (McLuhan, 1962, p. 31), the decision to migrate from regions of high depravity to that of abundance has become one decision away. In a classic book, entitled Ethnicities: Children of immigrants in America (2001), Ruben Rumbaut and Alejandro Portes painted an insightful assessment of the children of migrants. The duo correctly argued that it is a world of dilemma, risk and uncertainty. Considering today's motives for migration, it is an ecosphere in the continuum of the war and savagery. Displaced parents are in disarray, stampeding the children like collateral damage. In an article published in the same volume entitled "Straddling different worlds: The acculturation of Vietnamese refugee children", Min Zhou revealed how migrants' children are ushered into a besetting world of hopelessness as a direct consequence of their parents' "low socioeconomic status" (Zhou, 2001, p, 188). The writer also claimed the limiting environment that the children often found themselves collide them against failure, and unavoidably so. For being immigrants' children, traversing the 'difficult social terrain' and 'socioeconomic disadvantaged background' is a routine. However, the children also move against the tide, insurmountable as they are. Zhou (2001, p. 188) however argued that being straddled between "shrinking opportunity" and the growing desire to rise after each fall, could lead to one of two frustrations - "second-generation decline" (quoting Gans, 1992) or "second-generation revolt" (quoting Perlmann $\&$ Waldinger, 1997).

Thus, despite the significant uncertainties and psychological cost, what motivates migration? In other words, why do people migrate when the conditions are so precarious? Studies have established that migrant children's educational needs play a significant role in taking the crucial decision to migrate (Chen, Fromentin \& Zou, 2019; Liu \& Jacob, 2013) and in socially integrating the migrants into the host society (Coskun \& Coskun, 2018). Do the children of migrants stand any chance even when the socioeconomic conditions are favourable? How can we avoid the so-called 'second generation' contraption that bespeaks migrants' threatening situation in almost all societies? Can integration remove the trapping dilemma? With war, climate change, pestilences and pandemics, ethnic cleansing and terrorism ravaging especially in the Global South, and displacing people from their homes, how can we prepare for the inevitable eventuality of migrants? How should government prepare in these days of economic recession? This study interrogates these questions through the prism of scores of migrants' children of intra-continental and intra-state origins in Ile-Ife City in Nigeria. We explore the strategies adopted by the authorities of Ife Central Local Government in Ile-Ife, Nigeria to educate, train and integrate migrants' children. The study essentially dabbled into unravelling the possible multifaceted process of integration outcome that could be derived from educating the wards: for the society and the children themselves.

While a large volume of literature is available on various kind of migration within and into the North, there is the 
dearth of works on migratory movements within regions of the Global South. The classical work of Nasri Choucri and Peter Brecke published in 1983 and entitled "Migration in the Middle East: transformation and change" offers a great insight into migration within the Middle East. Nevertheless, the significant findings in the articles are a far cry to what obtains in the contemporary Middle East. In that work, Choucri and Brecke (1983) discovered several migratory patterns and rationale, which are mostly unrecognisable in today's movements in the region. For instance, current migration pattern within the region seems neither a temporary (maximum four-year) transfer of skilled and unskilled labour amidst the region's developing countries nor does it appears an inward movement from Asia, Turkey or Eastern Europe for occupational purposes. Today's migration in the Middle East can hardly be justified as underlined by politico-economic dynamics or chemo-tropic responses to facilitative policy for movement across national borders. If anything, the on-the-ground situation in the Middle East appears opposed to the submissions of Choucri and Brecke (1983). Nevertheless, the work continues to remain a reference point amidst the lack of other specialised publicly available scholarly work.

There are several studies on migration in Africa. Adepoju's (1998) classic study entitled "Linkages between internal and international migration: the African situation" appears to pioneer and explicate post-colonial situation within Africa. The author argued that until now when governments are curtailing unrestricted national boundarycrossing, internal cross-border migration within African states, albeit rural-rural and mostly by unskilled and agrarian people mainly for occupational and economic reasons, is the predominant human movement in Africa. Flahaux and De Haas (2016) argued that internal movements within Africa had waned tremendously since the independent era. The authors found that the latest reasons of social attraction to the Western values are replacing the old wisdom that destitution and violence drive the overwhelming outbound movement to Europe, USA and Canada, the Gulf and Asia for more than three decades till date. Contrariwise, Shimeles (2010) argued that migration within Africa outweighs emigration out of Africa. Shimeles (2010) however submitted that "motives to improve livelihoods", like Flahaux and De Haas (2016), dominates the motives for movements within or outside Africa. Lucas (2013) and Shaw (2007) substantially advanced the same reason and pattern. While the economyinduced rationale might still subsist, it is arguable that more reasons border on human survival from political, religious and violent conflicts, which induce migration in contemporary Africa. As Fischer and Vollmer (2009) pointed out, the motive for intra- and inter-continental migration in Africa is mainly forceful and hardly voluntary as available literature has flaunted it. The dynamics of intra-continental migration in Africa have not received commensurate attention. Yet, due to the outbreak of diseases, wars and civil unrests, religious violence and terrorism and a host of other internecine conflicts ravaging almost all parts of the continent, the movements of people within Africa have waxed the more in the recent time.

The epistemology of the study is built on two premises. One, the nature of internal migration in Africa is hardly temporary due to displacements and precarity of the crisis and fear of a resurgence of attacks in 'home' locations. Two, the nutritional needs of the migrants' wards, usually of growing age, is often over-flogged at the expense of humanitarian needs of training and education that would aid integration into the host communities. The study specifically examined the significant relationship between migrant children education and processes of integration. This article argued that school provides enabling environment for accelerated integration process through peer relationship, qualifications for gainful employment at a later date and refrains from crime. The paper is divided into six sections. The first section discusses the context of the study in term of migration and education of children in Ile-Ife. The second section examines migration, community and functionalism. The method used to collect data from the participants and the analytical techniques of the study was discussed in the third section. The section that presented the findings of the paper follows this. Finally, the conclusions of the study were presented.

\section{Context}

Ife Central Local Government Area (ICLGA) of the State of Osun in Nigeria is one of the four local government areas within Ile-Ife metropolis. Others are Ife East Local Government; Ife South Local Government; and Ife North Local Government areas. Of the estimated 540,000 inhabitants of Ile-Ife, the largest concentration of minimum projection of about 200,000 people live in ICLGA. Apart from the rural-urban drift that the local government grapples with on an annual basis from neighbouring rural local governments, there is also the seasonal challenge of migratory influx by citizens of Nigeria's neighbouring countries, which the current economic recession has exacerbated. The influx of migrants to Ile-Ife has started before the economic meltdown. Preliminary observation revealed that Ile-Ife is widely adjudged, by oral historical facts, to mainly attract these fleeing migrants as the acclaimed 'cradle' of civilisation and home of all Yoruba people and blacks in general. Besides, the typical magnanimity of Ile-Ife indigenous inhabitants towards 'strangers' from all walks of life is recognised in Africa's oral history and could easily be a factor in the influx (Folami \& Olaiya, 2016). Despite the current economic recession, the local government still maintains support for primary basic education for every child irrespective of 
socioeconomic background. The local government became focused on the education of migrants' children because of the encouraging education policy of the local administration. As Robin (2013) has pointed out, it is erroneous to believe that the main aim of primary education is to make children 'secondary-ready'; this undervalues children's potential for development and learning during the primary-education years. Even though education could provide fulcrums for present and future subsistence, contemporary studies have revealed that schools also address the broader condition and needs of children and society in today's complex world (Moscarola \& Kalwij, 2018; Kalwij, Alessie, Dinkova, Schonewille, Schors \& van der Werf, 2019; Parlinduncan, 2019). While primary and secondary schools are regarded as the vehicle for driving the importance of literacy and numeracy (Xie \& Tu, 2019), they also lay foundations in other areas - in spoken language, science, the arts, the humanities, and physical, emotional and moral development and proper integration into immediate society (Olaiya, 2020).

\section{Conceptual Clarifications: Migration, Humanitarian Action, and Functionalism}

There are different theories of migration, which explained the reasons why people moved from their homes to another community. The reasons for migration found explanations in the theories on migration. As noted in the introductory section, people migrated for socioeconomic, cultural and political reasons. Chiefly, this study is focussed on the current trend, pattern and rationale for intra-continent migration in Africa. There are currently a variety of theoretical models or perspectives that employ varying concepts, assumptions, frames and levels of analysis (Arango, 2000). Migration literature contends that the modern theoretical approaches offer different hypotheses; they need not be taken as mutually exclusive but rather as complementary. Theoretical perspectives on migration can be found in the following theoretical and empirical works such as the neoclassical theory of migration (Hicks, 1932); new economics theory of migration (Stark, 1991); World-systems theory (Massey et al. 1993; Sassen, 1988; Skeldon, 1997; Silver, 2003); dual labour market theory (Massey et al., 1993); network concepts (Vertovec, 2002; Dustmann and Glitz, 2005); Macro versus micro-explanations (De Haas, 2008). In this paper, the relevance of another broader sociological perspective on social understanding, tagged functionalism, is brought to fore. Functionalism is grounded in the survival of a social system. Though the theory was propounded in the $19^{\text {th }}$ century, the theory is still relevant to the explanation of the survival of a social system in a modern-day world. The theory found expression in this study to explain the survival of Ile-Ife as a social system against the backdrop of migrants influx into the city, which could create various social misdemeanour if basic education and proper integration of the growing migrants' infants are grossly lacking.

Provision of educational needs appears to fall outside the purview of traditional humanitarian action. The UN General Assembly resolution 46/182 of 1991 defined humanitarian action in terms of three essential componentshumanity, neutrality and impartiality (OCHA, 2015). Most literature on defined humanitarian action as the rescue mission to save lives, alleviate suffering and foster dignified lives of humans in times of war, political violence or natural disasters (OECD, 2012; OCHA, 2015; Gromes, 2019; Fröhlich, 2018; Coppi, 2018; Trithart; 2019; Fleischman, 2019; Carey, 1997-1998). The purport of this definition presupposes that humanitarian action may only be justified during emergency action. However, the provision of critical needs for migrants who are, most often, aliens in their new location makes the definition inaccurate. Debarre (2018) observed that "the nature of the crisis" that could warrant humanitarian action "is changing" (P. 1). The author argued "the idea of humanitarian action being strictly a short-term "Band-Aid" however, is increasingly ... inaccurate and even undesirable" (p. 1). As Atwood pointed out in OECD (2012), humanitarian action must be geared towards responding, not only to a crisis but also to critical conditions created by the aftermath of a crisis. Educating the children of migrants is an aftermath of a crisis that induced the people from moving away from their comfort zones.

Of particular relevance to this study is the Functionalism Theory of Talcott Parson, which the researcher adopted to explain the necessity of meeting the educational needs of immigrant children. Functionalism Theory states that survival of a system depends on adaptation, goal, integration and latent pattern maintenance (AGIL). Studies on the educational needs of children borrowed extensively from functional prerequisite to explain integration and avoidance of conflict between immigrants and the host community. Functionalism theory is a different theory of conflict theory. Social conflict theory has its roots in Marxism which argues that individuals and groups within society have differing amounts of material and nonmaterial resources and that the most influential groups use their power in order to exploit groups with less power. Functional prerequisite, a theory propounded by Talcott Parson, was used in the paper to explain the justification for equality, equity, integration, needs, accommodation and development. The theory explained how Ile-Ife could be sustained in the face of mass migration of aliens into the city.

It should be noted that Nigeria generally is experiencing an economic recession. The recession has affected the income of the Local Government Authorities across the State. According to Ritzer (2006), functional prerequisite explains socioeconomic adaptation, societal goals attainment, integration and latent pattern maintenance (AGIL). 
The AGIL schema, as discussed by Talcott Parson (1969), implicates that a society can survive by following the direction of adaptation, goal, integration, and latent pattern maintenance. First, adaptation explains how a social system must be able to cope with external exigencies, i.e. a system cannot be an Island to itself because of the external forces around which he is propelled to cope with. The system must be able to adapt to its environment and adapts to the needs of its environment. Second, goal attainment finds explanation in a situation where a system must be of necessity defined and achieved its goals, aims and objectives. Third, integration explains as a method where a system regulates the inter-relationship of its parts. It must also manage the relationship between the other three functional prerequisites. Fourth, latent pattern maintenance suggests that a system must furnish, maintain and renew both motivation of individuals and their cultural peculiarities.

Critically looking at the functionalist theories and its relevance to the explanation of the problem of migration in recent times, the underlying explanation for the survival of the host community is the integration of migrants. The integration will ensure that cultural patterns are maintained, which, in a way, could guarantee self-esteem and peaceful coexistence. The migration may prevent the second level of disequilibrium to the migrants, and it may not trigger the social disorder in the host community. Though AGIL provides explanations on integration and security: it nevertheless failed to explain the sources of resource to maintain the security and social order. The theory also failed to discuss how to maintain both latent and manifest aspect of security. Based on the theoretical analysis, this paper asked the following research questions: What are the critical conditions for which migrants' children may be subjected to educational and integration needs? What are the coping mechanisms available to the local government authority? How could a local government authority as the third tier of government meet the enormous educational needs of migrants' children? Could the provision of the educational needs of migrant children lead to their integration? It is essential to have it in mind that this paper focuses majorly on the educational needs of migrant children in Ile-Ife. Meeting the educational needs of migrant children by the local government will serve two essential purposes: (1) integration; and (2) security. The two purposes serve symbiotically to both the migrants and the host community.

The overarching conceptual import of this research is represented in the schema in Figure 1. Empowered governance at the grassroots, through the provision of more funding, is set to ultimately enhance social integration by way of acculturation and reduction in crimes migrant-related to crime. The permeable membrane is the gearing of humanitarian action into providing basic education for migrant children.

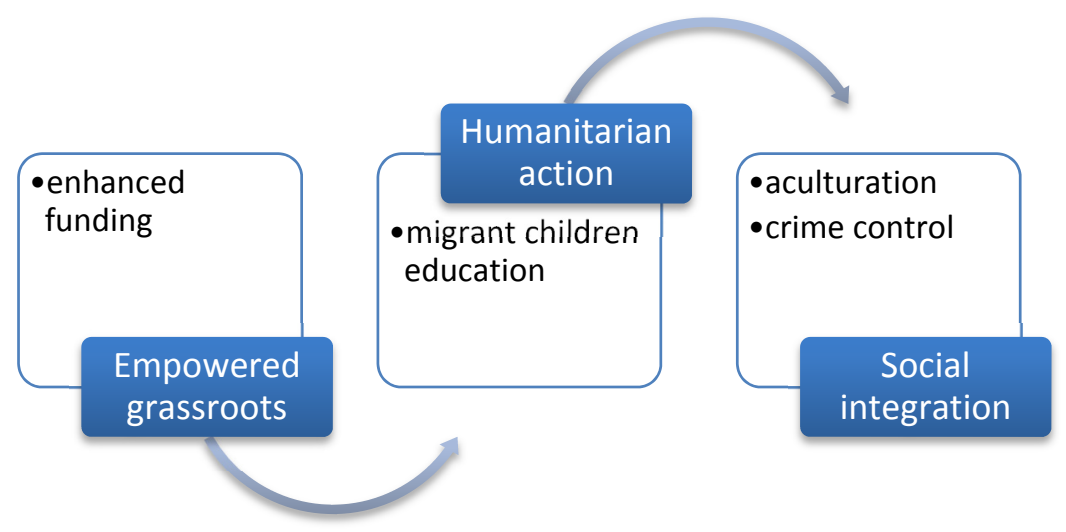

Figure 1. Humanitarian action nexus to social integration at the grassroots

\section{Materials and Method}

The study adopted a cross-sectional survey undertaken in Ife Central Local Government, the coordinating local government in Ile-Ife region of Osun State, Nigeria. Ile-Ife is the acclaimed cradle of Yoruba race with abundant historical evidence dating back to $800 \mathrm{BC}$ (Willett, 1960). Ile-Ife as presently constituted comprises four Local Government areas, namely, Ife Central, Ife East, Ife North and Ife South Local Government Areas. Ile-Ife shared boundary with Osun in the West, Oke-Igbo in the South, and Ilesa in the East. Willett (1960, p. 232) had referred to Ile-Ife as a 'prosperous town of about 150,000 inhabitants'. As at 2005 , when the only nationally acceptable census was carried out and published in Nigeria, each of the four local governments in Ile-Ife has the population of about 135,000 (National Population Census, 2006). According to government records accessed in ICLGA, there are over 50,000 non-indigenes of Ile-Ife such as Igbo, Hausa, Urhobo, Ijaw, Fulani, and over 15,000 foreigners in 
Ile-Ife metropolis.

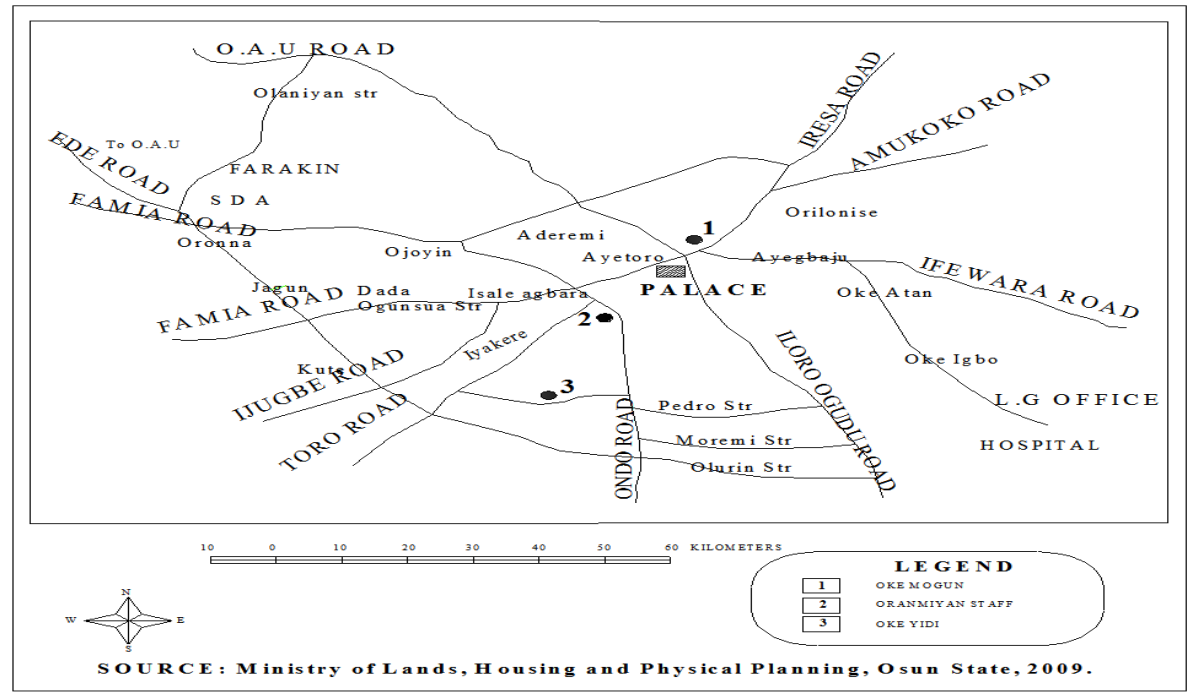

Figure 2. Map of Ile-Ife

\subsection{Participants}

The selection of participants in this study was made through simple randomisation. A total of two hundred and fourteen participants were selected among the workers of Ife Central Local Government Area: Welfare Department 46; Community Development \& Security Committee (CDSC) 63, Education Department 35; Office Holders 08; Special Primary Education Board 39 and Finance Department 23. The list of workers in the Department of the Local Government was used on a two-scale interval to select the number of participants in this study. The method adopted allowed the inclusion of gender, age categories, years of experiences and different qualifications in the study. The study adopts survey design and primary data collection method to collect information from two hundred and fourteen participants. The participants comprised education and welfare staffs of the local governments, migrants from neighbouring countries, civil society officials, officials of NGOs, officials of Community-Based Organisations, notable traditional titleholders and key informants. A structured questionnaire, containing close and open-ended questions, was designed to elicit appropriate information. Personal interviews were conducted on selected migrant leaders for triangulation and to elicit information on acculturation.

\subsection{Data Collection and Analysis}

The quantitative method of primary data collection was used to collect information from two hundred and fourteen participants. A structured questionnaire, containing close-ended standardised questions, was designed to collect the data. Secondary data were also collected from the Welfare Department of the ICLG to elicit information about the origin and age distribution of the migrants' children under the educational needs of the local government. Both descriptive and inferential statistics were utilised for analysis, which is respectively dichotomy test of reliability, cross-tabulations and chi-square to analyse data collected from the field. The variable considered in this included: origin, age, education, need, finance, space, teacher, language, and integration. All the variables are independent, hence the suitability of the chosen inferential statistical technique. 


\section{Results}

\subsection{Migrant Children's Education, Integration and Crime Proclivity}

Table 1. Showing dichotomy intervals of migrant children's education

\begin{tabular}{lllllll}
\hline & \multicolumn{3}{l}{ \% Yes } & \multicolumn{2}{l}{ \% No } & \multicolumn{2}{c}{ Dichotomy Interval } \\
\hline Department & MI & MCP & MI & MCP & MI & MCP \\
Welfare: Medical and Environmental & 16.8 & 19.2 & 4.7 & 2.3 & 3.6 & $8.3^{*}$ \\
Community Dev. \& Security Com. & 27.6 & 24.3 & 1.9 & 5.1 & $14.5^{*}$ & $4.8^{*}$ \\
Education Department & 12.6 & 12.1 & 3.7 & 4.2 & 3.4 & 2.9 \\
Office Holders & 2.8 & 2.8 & 0.9 & 0.9 & 3.1 & 3.1 \\
Special Primary Education Board & 13.1 & 12.1 & 5.1 & 6.1 & 2.6 & 2.0 \\
Finance & 7.9 & 7.5 & 2.8 & 3.3 & 2.8 & 2.3 \\
Total & 80.8 & $\mathbf{7 8 . 0}$ & $\mathbf{1 9 . 2}$ & $\mathbf{2 2 . 0}$ & $4.2^{* *}$ & $3.5^{* *}$ \\
\hline
\end{tabular}

Source: Field report, 2018

Key:

MI: Migrant's Integration MCP: Migrant's Crime Proclivity

* Group dichotomy $\quad$ ** Overall dichotomy

Both dichotomy intervals of migrant children's education in relation to migrant integration and crime proclivity, represented in Table 1, are valid for reliability test. The Community Development and Security Committee had a greater dichotomy interval than the overall figure. The dichotomy interval is a reliability test that represents the percentage gap between dichotomous responses within a group of respondent compared with the overall total. For a dichotomy distribution to be valid, at least one of the groups must record a gap that is greater than the overall gap. The higher the group gap compared to the overall gap, the stronger the extent of reliability of opinion expressed in that group. Despite migrant's crime proclivity recording double group intervals $(8.3,4.8)$, migrant's integration received a more substantial boost (14.5) from migrant children's education. In other words, the provision of basic education for migrant children would impacts more on migrant integration than reducing migrant crime proclivity.

Table 2. Integration and host community security from Migrant children's education

\begin{tabular}{lllll}
\hline & $\aleph^{2}$ & $\alpha$ & Degree of freedom & Critical value \\
\hline Integration & 11.2 & 0.025 & 2 & 8.5 \\
Host community security & 10.2 & 0.025 & 1 & 6.1 \\
\hline
\end{tabular}

Source: Field report, 2018

Table 2 represents the test of association between migrant children's education, and migrant's integration and host community's benefit respectively. For both, the observed $\aleph^{2}$ surpassed the critical values. Inferences, thus, reveal that both migrant's integration and host community security are associated with the provision of basic education to migrant children in the locality.

\subsection{Acculturation of Migrants}

Migrants within Nigeria and those from neighbouring states are classified as intra-continental migrants. Content analysis of the interview responses is presented in Figure 3. 


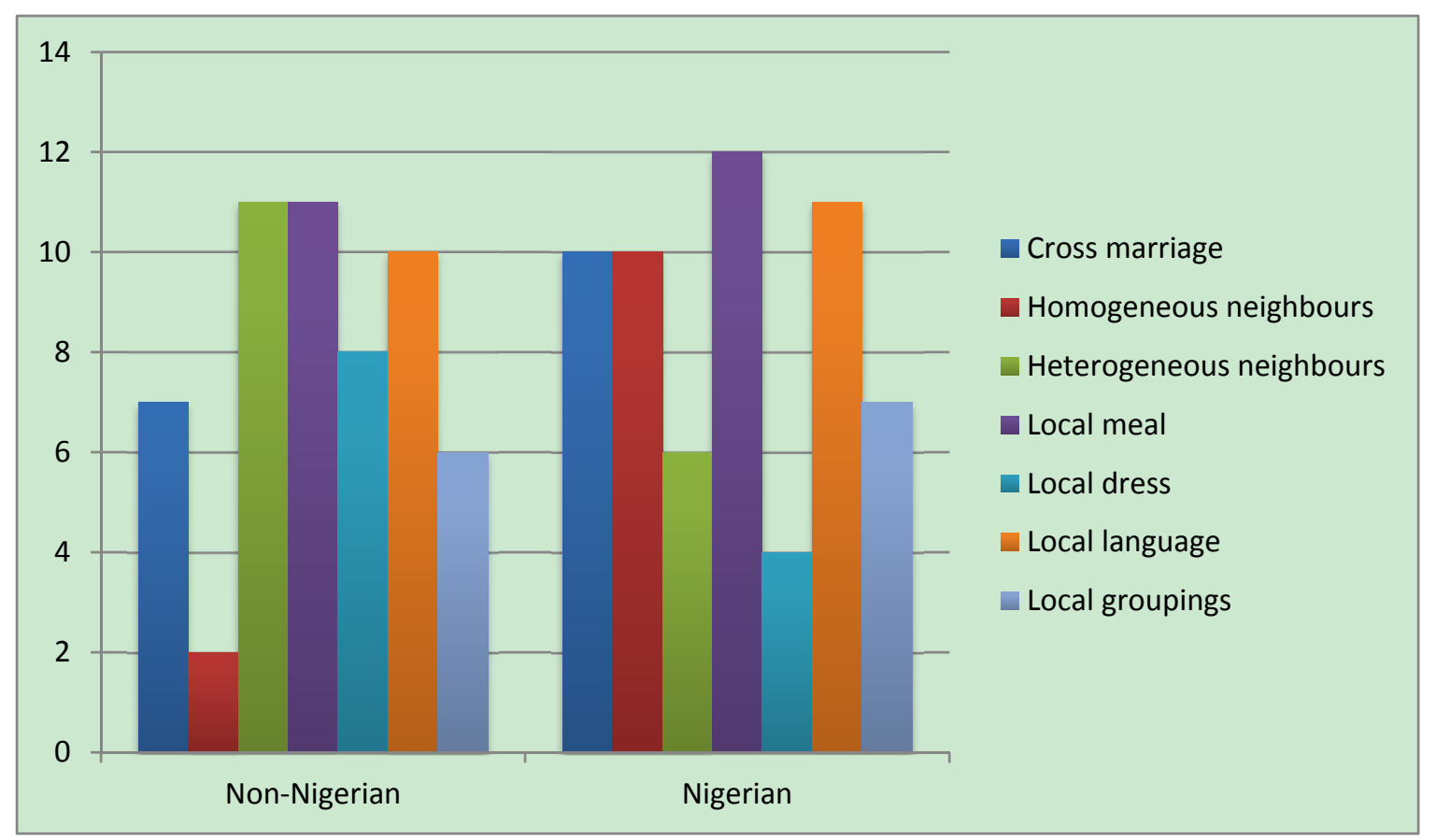

Figure 3. Coded preferences for acculturation

Source: Field reports, 2018

Figure 3 represents the coded preferences from a content analysis of interview responses of both non-Nigerian and Nigerian migrants within the local area. The measuring yardstick from reputable writers in acculturation (Ward \& Kennedy, 1994; Berry, 1997; Ward \& Rana-Deuba, 2009; Berry, 2005; Güzel \& Glazer, 2019) was adopted as a guiding framework to measure the process of acculturation of the migrants. We found migrant acculturation in this area to be profoundly influenced by (1) migrant adaptation while unconsciously pursuing assimilation, (2) migrant tendency to blend original identity with local culture (3) strong identifications with the host community, and (4) migrant localising and interaction. In place of these, we extracted seven focal points, namely, cross marriage with host spouses, living among members of the migrant ethnic group only, residing among heterogeneous neighbours most of whom are likely to be members of the host community, and preference for grouping with local associations consisting of host community members and other ethnic groups. We also extracted migrant preferences for meals, dressing and language of the host community. In the end, both Nigerian and non-Nigerian migrants showed a high propensity to assimilate into the host community, given unique opportunities like the provision of basic education for their offspring.

\section{Discussion of Findings}

In this study, structural functionalism was carefully selected to explain the education needs of migrant children in Ife Central Local Government Area. This line of reasoning is needed to articulate the extent to which the continued peace and tranquillity of the local government area depends on accommodation and integration of the migrants. Structural Functionalism Theory explains the importance of functional prerequisites to the survival of a social system. Ife Central Local Government Area could be considered as a social system because its essence is to serve the members of Ile-Ife community. Local government, being the third level of government in Nigeria, is limited by relevant factors like funding, independence in decision-making and control of migration. Structural Functionalism Theory is therefore employed here to explain the survival of the local government area in the current influx of migrants. Out of four prerequisites mentioned by Talcott Parson (stated earlier), integration was extensively singled out in this study to explain:

How the integration of migrant children was necessary as a means of support and security for Ile-Ife metropolis;

How the migration could be linked to the development of the migrants' children within the Ile-Ife community in general; and

How the provisioning of education needs for migrants' children by ICLGA is of mutual benefit to both: whereas 
the beneficiaries are invested with opportunities for personal survival in the positive direction, the benefactor's aggregate human capital is multiplied according to the diversity of migrants.

Therefore, the use of variable such as integration features extensively throughout the paper. The theories of migration that were carefully considered in this study included the neoclassical theory of migration (Hicks, 1932); new economics theory of migration (stark, 1991); World-systems theory (Massey et al. 1993; Sassen 1988; Skeldon 1997; Silver 2003); dual labour market theory (Massey et al., 1993); network concepts (Vertovec 2002; Dustmann and Glitz 2005); Macro versus micro-explanations (de Haas 2008). Functional prerequisites AGIL is closely related to de Haas (2008) macro and micro explanations of migration, which I think has contributed more to the understanding of migration problem.

Attempts to explain the necessities for educating migrant children revealed the importance of education. The importance of basic education as was revealed in the literature is beyond the preparation of pupils for the higher challenges. It includes meeting the psychological and social needs of pupils. The study revealed that the education of migrant children was essential to secure the future of migrants' children and the host community. The result of the inferential analysis that explored the significant relationship between education needs and benefits to the host community further strengthens the discoveries as to the critical reasons why migrants' children should be supported. The study discovered that the migrants' children need the service of psychologists to be able to cope in the new environment where they might be experiencing culture shock. We reckon with the oft-cited work of Oberg (1960, p. 142) on how culture shock may tend to lead to occupational diseases for especially children who suddenly got 'transplanted abroad'. This finding has found expression in many studies of note since the 'honeymoon' stage of culture shock often disappear very fast and get replaced by strain, fear of survival and rashness (Mumford, 1998; Smalley, 1963; Oberg, 1960). Thus it might be much more necessary to maintain the children in their present circumstances psychologically. It was revealed that the Local Government absorbed migrants' children in the existing primary schools to facilitate their integration and inclusive processes.

Furthermore, The importance of educating migrant children associates with integration. With education, the participants believe that it becomes progressively easier to integrate migrant children with other members of the community. The result of inferential analysis on the significant relationship between education needs and integration supported the notion that education needs can aid the integration of migrants' children. This finding is in line with the submission of Allport (1954) who explored the crucial ingredients of integration of pupils to achieve equal status, common goal, contact and healthy competition. To achieve education and integration of migrant children, the fund must be available. Interview responses revealed that funding education needs of migrant children are a significant challenge. Respondents advocated for internally generated revenues instead of the existing funding from a statutory monthly allocation from the federation account, borrowing and other sources like grants, sales of bonds and treasury bills. This finding is perhaps a little surprising and, perhaps realistic. It runs contrary to the findings from some works that submitted that education is better funded from the statutory allocation (Khemani, 2001; Akeem, 2011; Ikeji, 2011; Oseni, 2012). For Olaiya, (2016), Lamidi and Fagbohun (2013) and Khemani (2001), the Nigerian local government can only fare better in service delivery with increased statutory allocation from the federation accounts. Nevertheless, the findings are in tandem with notable works like Ubogu (2011), who found that funding education in Nigeria should involve contributions from all stakeholders in the form of taxes and other internally generated revenue. Moreover, the findings of this study are realistic as it expresses the practical situation of economic recession currently affecting revenue inflow from the federation account due to collapse of crude oil prices from where over $90 \%$ of the funds accrued.

Finally, existing research shows that continental nature of migration into North America, Europe and some parts of Asia plays a vital role in shaping the acculturation of the migrants (Redfield, Linton \& Herskovits, 1935, Das, 2019; Gindelsky, 2017; Beals, 1951; Kessler \& Milligan, 2019; Thompson, 1948; Ahmmad \& Adkins, 2019; Liu, 2017; Kodja \& Lebedeva, 2018; Groenewold \& de Valk; Kodja \& Ryabichenko, 2019). The common trend is that continental migrants reserve little or no option in acclimatising in the new environment. In other words, continental migrants often quickly adopt the cultural settings of the host community since they have few options to relate otherwise. Incidentally, this research found expressions with these classic and contemporary studies that, given unique chances of basic education for migrant children, intra-continental migration is not debased by acculturation. Thus, a migrant within the African continent is expected to find no problem with acculturation in cases where educating his or her children is guaranteed.

\section{Conclusion}

Regarded as Europe's dilemma in contemporary time, most documented pieces of evidence of the challenges posed by the influx of immigrants into host nations are gathered from European nations. The fact appears sacrosanct that 
the influx and the attendant challenges of immigrants from the Middle East and North Africa are unprecedented and concentrated in that part of the world. Nevertheless, the excessive movement of people from crisis-ridden areas for economic and physical safety is arguably a global issue. Latent in the thesis of this study is the quest to explore the relationship between migration and educational development. As Olaiya (2020) and Skeldon (1997) argued, the relationship between migration and development is complex, multifocal, and yet intuitively simple. To underscore the points in this study, the notion of migration was conceptually defined; neither by the transitional movement of population from rural to urban societies nor by a population-mobility-induced transit from one society (usually economically or politically backward) to a more advanced one. We construed the movement of people motivated by economic strain, environmental conditions and human-induced violence as the operational connotation of migration. The complexity in 'development' was equally disaggregated into precisely focused dimensions of integration- which in itself is complex but simplified here to denote readiness to be accepted and actual acceptance by the social setting of the host community, Ile-Ife Metropolis. Development was also seen as the opportunity cost of migrant-related crimes. In other words, the study explores the investments that could be channeled today, not to acculturate the migrants particularly, but to ease their mutual existence from a multicultural perspective.

The paper, therefore, concluded that total integration of migrants' children would improve their welfare, sets a pace for future progress and prevent the children from committing crimes that could result in an undue clash with local inhabitants. The host community will benefit tremendously from the human capacity outputs of the migrants and their integration. The paper suggested, among others, that more investment from major international humanitarian institutions, in collaboration with the Local Government on education, remain a critical issue in ameliorating the education need of children. This will enhance the physical and emotional needs of the migrants' children, social integration and proactively debar crime at the grassroots.

\section{References}

Acar, I. H. (2013). Early childhood development and education through nature-child interactions: A conceptual paper. The International Journal of Educational Researchers, 4(2), 1-10.

Adepoju, A. (1998). Linkages between internal and international migration: The African situation. International Social Science Journal, 50(157), 387-395. https://doi.org/10.1111/1468-2451.00151

Ahmmad, Z., \& Adkins, D. E. (2019). Ethnicity and acculturation: Asian American substance use from early adolescence to mature adulthood. Retrieved from https://ssrn.com/abstract $=3415993$

Akeem, U. O. (2011). Revenue allocation formula and its impact on economic growth process in Nigeria. Journal of Economics and Sustainable Development, 2(3), 29-37.

Allport, G. W. (1954). The nature of prejudice. London: Addison Wesley.

Arango, J. (2000). Explaining migration: A critical view. International Social Science Journal, 52(165), 283-296. https://doi.org/10.1111/1468-2451.00259

Beals, R. L. (1951). Urbanism, urbanisation and acculturation. American Anthropologist, New Series, 53(1), 1-10. https://doi.org/10.1525/aa.1951.53.1.02a00020

Bergh, A., \& Gustafsson, A. (2019). Globalisation and populism in Europe. IFN Working Paper No. 1304. https://doi.org/10.2139/ssrn.3489924

Berry, J. W. (1997). Immigration, acculturation, and adaptation. Applied Psychology: An International Review, 46, 5-68. https://doi.org/10.1111/j.1464-0597.1997.tb01087.x

Berry, J. W. (2005). Acculturation: Living successfully in two cultures. International Journal of Intercultural Relations, 29, 697-712. https://doi.org/10.1016/j.ijintrel.2005.07.013

Carey, H. F. (1997-1998). The UN Humanitarian Intervention in Haiti and the Development of a Human Rights Enforcement Regime. Journal of Haitian Studies, 3\&4, 30-47.

Chen, Y., Fromentin, V., \& Zou, B. (2019). To migrate with or without ones' children in China - That is the question. Annals of Economics and Statistics, 135, 69-88. https://doi.org/10.15609/annaeconstat2009.135.0069

Choucri, N., \& Brecke, P. (1983). Migration in the Middle East: Transformation and change. In Migration in the Middle East: Transformation, policy and processes (Vol. 2, pp. 16-27). Technology adaptation program report No. 83-3: Cambridge, Massachusetts: Massachusetts Institute of Technology.

Coppi, G. (2018). Challenges and opportunities for the humanitarian response: The humanitarian crisis in Yemen: Beyond the man-made disaster. International Peace Institute. 
Coskun, B. B., \& Coskun, G. B. (2018). Primary and secondary level education models in migrant integration: A comparative analysis of the cases of Britain, Germany and Turkey. Working Paper 11 of the Association for Development of Migration and Social Policies.

Cox, M. (2017). The rise of populism and the crisis of globalisation: Brexit, Trump and beyond. Irish Studies in International Affairs, 28, 9-17. https://doi.org/10.3318/isia.2017.28.12

Das, M. (2019). Ethnic identity impact on consumers' ethnocentric tendencies: The moderating role of acculturation and materialism. Management and Labour Studies, 45(1). https://doi.org/10.1177/0258042X19890245

De Haas, H. (2008). Migration and development: A theoretical perspective. International Migration Institute Working Paper no.9. The University of Oxford.

Debarre, A. (2018). Humanitarian action and sustaining peace. International Peace Institute.

Dixon, V. K. (2009). Understanding the implications of a global village. Inquiries Journal, 1(11). Retrieved from http://www.inquiriesjournal.com/a?id=1681

Dustmann, C., \& Albrecht, G. (2005). Immigration, jobs and wages: Theory, evidence and opinion. Centre for Research and Analysis of Migration, CEPR, London.

Fischer, C., \& Vollmer, R. (2009). Migration and displacement in Sub-Saharan Africa: The security-migration nexus II. Brief No. 39 of an International Conference organised by Bonn International Center for Conversion on 13-14 February 2009 in Bonn. Retrieved September 23, 2016, from https://www.bicc.de/uploads/tx_bicctools/brief39.pdf

Flahaux, M. L., \& De Haas, H. (2016). African migration: Trends, patterns, drivers. Comparative Migration Studies, 4(1), 1-25. https://doi.org/10.1186/s40878-015-0015-6

Fleischman, J. (2019). Multilateral humanitarian system and other donors: How can we better reach women and girls in crises? Center for Strategic and International Studies (CSIS).

Flew, T., \& Iosifidis, P. (2020). Populism, globalisation and social media. International Communication Gazette, 82(1), 7-25. https://doi.org/10.1177/1748048519880721

Folami, O. M., \& Olaiya, T. A. (2016). Gender, storytelling and peace construction in a divided society: a case study of the Ife/Modakeke conflict. Cogent Social Sciences, 2(1), 1-19. https://doi.org/10.1080/23311886.2016.1159015

Frohlich, C. (2018). Shrinking spaces of humanitarian protection. German Institute of Global and Area Studies (GIGA).

Gindelsky, M. (2017). Testing the acculturation of the 1.5 generation in the United States: Is there a 'critical' age of migration? Review of Economics of the Household, 17(1), 31-65. https://doi.org/10.1007/s11150-0179400-2

Groenewold, G., \& de Valk, H. A. G. (2017). Acculturation style, transnational behaviour, and return-migration intentions of the Turkish second generation: Exploring linkages. Demographic Research, 37, 1707-1734. https://doi.org/10.4054/DemRes.2017.37.53

Gromes, T. (2019). Humanitarian military interventions since the second World War: A humanitarian milestone? NATO's 1999 intervention in Kosovo and trends in military responses to mass violence. Peace Research Institute in Frankfurt.

Güzel, H., \& Glazer, S. (2019). Demographic correlates of acculturation and sociocultural adaptation: Comparing international and domestic students. Journal of International Students, 9(4), 1074-1094. https://doi.org/10.32674/jis.v10i1.614

Hicks, J. R. (1932). The theory of wages. London: Macmillan.

Ikeji, C. C. (2011). Politics of revenue allocation in Nigeria: A reconsideration of some contending issues. Sacha Journal of Policy and Strategic Studies, 1(1), 121-136.

Kalwij, A., Alessie, R., Dinkova, M., Schonewille, G., van der Schors, A., \& van der Werf, M. (2019). The effects of financial education on financial literacy and savings behaviour: Evidence from a controlled field experiment in Dutch primary schools. The Journal of Consumer Affair, 53(3), 699-730. https://doi.org/10.1111/joca.12241

Kessler, A. S., \& Milligan, K. S. (2019). Acculturation, education, and gender roles: Evidence from Canada. CEPR 
Discussion Paper No. DP13658. Retrieved from https://ssrn.com/abstract=3372856

Khemani, S. (2001). Fiscal federalism and service delivery in Nigeria: The role of states and local governments. A public sector prepared for the Nigerian PER Steering Committee. Retrieved October 1, 2016, from http://www1.worldbank.org/publicsector/decentralization/March2003Seminar/FiscalFedReport.pdf

Kodja, E., \& Lebedeva, N. (2018). The role of multiple identities and acculturation strategies in psychological well-being of Crimean Tatars. Higher School of Economics Research Paper No. WP BRP 97/PSY/2018. Retrieved from https://ssrn.com/abstract=3269231

Kodja, E., \& Ryabichenko, T. (2018). The relationship between social identities, Acculturation strategies and the psychological well-being of young Russians in Latvia and Crimean Tatars in Crimea. Higher School of Economics Research Paper No. WP BRP 111/PSY/2019. Retrieved from https://ssrn.com/abstract=3495090

Lamidi, O. K., \& Fagbohun, F. O. (2013). Advocating for direct revenue allocation to Nigerian local governments: A catalyst for national development. Journal of Public Administration and Policy Research, 5(6), 133-140. https://doi.org/10.5897/JPAPR2013.0249

Liu, J., \& Jacob, W. J. (2013). From access to quality: Migrant children's education in urban China. Education Research for Policy and Practice, 12, 177-191. https://doi.org/10.1007/s10671-012-9136-y

Liu, M. (2017). The effect of acculturation on extreme response style: A mediation analysis among a sample of Arab American adults. Retrieved from https://ssrn.com/abstract=2996218

Massey, D. S., Arango, J., Hugo, G., Kouaci, A., Pellegrino, A., \& Taylor, J. E. (1993). Theories of international migration: A review and appraisal. Population and Development Review, 19(3) 431-466. https://doi.org/10.2307/2938462

McLuhan, M. (1962). The Gutenberg galaxy: The making of typographic man. University of Toronto Press.

McLuhan, M. (1964). Understanding media: The extensions of man. McGraw-Hill.

Moscarola, F. C., \& Kalwij, A. (2018). How informal education affects the financial literacy of primary school children developed in a formal educational program. Discussion Paper185/18. Center for Research on Pensions and Welfare Policies, Turin.

Mumford, D. B. (1998). The measurement of culture shock. Social Psychiatry and Psychiatric Epidemiology, 33(4), 149-154. https://doi.org/10.1007/s001270050037

Oberg, K. (1960). Cultural shock: Adjustment to new cultural environments. Practical Anthropology, 7, 177-182. https://doi.org/10.1177/009182966000700405

OCHA. (2015). Introduction to humanitarian action: A brief guide for resident coordinators. OCHA.

OECD. (2012). Towards better humanitarian donorship: 12 lessons for DAG peer reviews. OECD.

Olaiya, T. A. (2016). Governance and constitutional issues in the Nigerian local government. Journal of Politics and Law, 9(1), 21-34. https://doi.org/10.5539/jpl.v9n1p21

Olaiya, T. A. (2020). Migration, employment policy and social integration: Evidence from Nigeria. Journal of Public Administration and Governance, 10(2). https://doi.org/10.5296/jpag.v10i2.16719

Oseni, M. (2012). Adequacy of budgetary allocation to educational institutions in Nigeria. Pakistan Journal of Business and Economic Review, 3(1), 143-157.

Osman, W. (2019). Media and imperialism in the global village: A case study of four Malalais. In A. Punathanbekar, \& S. Mohan (Eds.), Global digital cultures: Perspectives from South Asia (pp. 280-296). University of Michigan Press.

Parlindungan, F. (2019). Understanding children development from literacy perspective: Critique of competing theories. Conference paper presented at the 1st International Conference on Public Health Universitas Teuku Umar, 18 November 2019.

Pieterse, M. (2003). Equality in the global village. The Comparative and International Law Journal of Southern Africa, 36(2), 172-197.

Redfield, R., Linton, R., \& Herskovits, M. J. (1935). Acculturation. Oceania, 6(2), 229-233. https://doi.org/10.1002/j.1834-4461.1935.tb00183.x

Robin, A. (2013, October, 4). Eight priorities to improve primary education. The Guardian. Retrieved September 23, 2016, from https://www.theguardian.com/teacher-network/teacher-blog/2013/oct/04/priorities-improve- 
primary-education

Rodrik, D. (2018). Populism and the economics of globalisation. Journal of International Business Policy, 1, 1233. https://doi.org/10.1057/s42214-018-0001-4

Rumbaut, R. G., \& Portes, A. (2001). Introduction: Exogenesis: Coming of age in immigrant America. In R. G. Rumbaut, \& A. Portes (Eds.) Ethnicities: Children of immigrants in America (pp. 1-20). Los Angeles, CA: University of California Press. https://doi.org/10.1525/california/9780520230118.003.0001

Sassen, S. (1988). The mobility of labor and capital. A study of international investment and labor flows. Cambridge: Cambridge University Press. https://doi.org/10.1017/CBO9780511598296

Scott, B. R. (2001). The Great Divide in the Global Village. Foreign Affairs, 80(1), 160-177. https://doi.org/10.2307/20050050

Shaw, W. (2007). Migration in Africa: A review of the economic literature on international migration in 10 $\begin{array}{llllll}\text { Countries. } & \text { A } & \text { World } & \text { Bublication } & \text { Retrieved from }\end{array}$ http://siteresources.worldbank.org/INTPROSPECTS/Resources/3349341110315015165/Migration_in_Africa_WilliamShaw.pdf

Shimeles, A. (2010). Migration patterns, trends and policy issues in Africa. A Working Paper No. 119 of the African Development Bank Group.

Silver, B. (2003). Forces of labor: Workers' movements and globalisation since 1870. Cambridge: Cambridge University Press. https://doi.org/10.1017/CBO9780511615702

Skeldon, R. (1997). Migration and development. A global perspective. London, UK: Routledge Taylor and Francis.

Smalley, W. A. (1963). Culture shock, language shock, and the shock of self-discovery. Practical Anthropology, 49-56.

Smith, A. (1776). An inquiry into the nature and causes of the wealth of nations (Metalibri Digital Edition 2007). New York: Metalibri. https://doi.org/10.1093/oseo/instance.00043218

Stark, O. (1991). The migration of labor. Cambridge: Basil Blackwell.

Terry, F. (2019). Populism and globalisation: Towards a Post-Global Era? Retrieved from https://ssrn.com/abstract $=3321448$

Thompson, L. (1948). Attitudes and acculturation. American Anthropologist, New Series, 50(2), 200- 215. https://doi.org/10.1525/aa.1948.50.2.02a00020

Ubogu, E. (2011). Financing higher education in Nigeria. Journal of Research in Education and Society, 2(1), 3645.

Vertovec, S. (2002). Transnational networks and skilled labor Migration. Paper presented at the conference: Ladenburger Diskurs “Migration” Gottlieb Daimler- und Karl BenzStiftung, Ladenburg, 14-15 February.

Ward, C., \& Kennedy, A. (1999). The measurement of sociocultural adaptation. International Journal of Intercultural Relations, 23, 659-677. https://doi.org/10.1016/S0147-1767(99)00014-0

Ward, C., \& Rana-Deuba, A. (1999). Acculturation and adaptation revisited. Journal of Cross-Cultural Psychology, 30, 422-442. https://doi.org/10.1177/0022022199030004003

Willett, F. (1960). Ife and its archaeology. The Journal of African History, 1(2), 231-248. https://doi.org/10.1017/S002185370000181X

Xie, J., \& Tu, Y. (2019). An investigation into the impact of mindfulness education on children developmentbased on the mindfulness experiment on 5th graders of d primary school in W city. Best Evidence of Chinese Education, 2(2), 229-242. https://doi.org/10.15354/bece.19.ar1049

Zhou, M. (2001). Straddling different worlds: The acculturation of Vietnamese children. In R. G. Rumbaut, \& A. Portes (Eds.), Ethnicities: Children of immigrants in America (pp. 1-20). Los Angeles, CA: University of California Press. https://doi.org/10.1525/california/9780520230118.003.0007 


\section{Copyrights}

Copyright for this article is retained by the author(s), with first publication rights granted to the journal.

This is an open-access article distributed under the terms and conditions of the Creative Commons Attribution license (http://creativecommons.org/licenses/by/4.0/). 